Article

\title{
Investigation on the Stability of Derivative Melam from Melamine Pyrolysis under High Pressure
}

\author{
Xiaohong Yuan ${ }^{1}$, Kun Luo ${ }^{1,2}{ }^{\mathbb{D}}$, Yingju Wu ${ }^{1}$, Julong He ${ }^{1}$, Zhisheng Zhao ${ }^{1, *(\mathbb{D})}$ and Dongli Yu ${ }^{1, *}$ \\ 1 State Key Laboratory of Metastable Materials Science and Technology, Yanshan University, \\ Qinhuangdao 066004,China; xhyuan_future@163.com (X.Y.); hiluokun@gmail.com (K.L.); \\ wuyingjv@163.com (Y.W.); hjl@ysu.edu.cn (J.H.) \\ 2 Hebei Key Laboratory of Microstructural Material Physics, School of Science, Yanshan University, \\ Qinhuangdao 066004, China \\ * Correspondence: zzhao@ysu.edu.cn (Z.Z.); ydl@ysu.edu.cn (D.Y.); Tel.: +86-0335-8057-047
}

Received: 1 March 2018; Accepted: 16 March 2018; Published: 18 March 2018

\begin{abstract}
Although various kinds of carbon nitride precursors have been proposed, s-triazine-based structures are hardly reported because of their unfavorable energy, higher than that of heptazine-based ones. In this study, we investigate the thermal stability of s-triazine-based melam processed at a high pressure of $5 \mathrm{GPa}$ and a temperature of $400-700{ }^{\circ} \mathrm{C}$ and complete the analyses of the composition and structure of the treated samples through X-ray diffraction (XRD), Fourier-transform infrared spectroscopy (FTIR), and elemental analyses (EA). Results show that melam can stably exist up to $600{ }^{\circ} \mathrm{C}$ at $5 \mathrm{GPa}$. XRD and FTIR analyses reveal that residual melamine can be pyrolyzed into melam as temperature increases from $400{ }^{\circ} \mathrm{C}$ to $600^{\circ} \mathrm{C}$ at a high pressure, suggesting that melam may be purified through high-pressure pyrolysis. Further melam polymerization at a higher pressure is a promising strategy for the preparation of s-triazine-based carbon nitride precursors used for bulk carbon nitride synthesis.
\end{abstract}

Keywords: melamine; melam; high pressure; pyrolysis; s-triazine; $\mathrm{g}-\mathrm{C}_{3} \mathrm{~N}_{4}$

\section{Introduction}

Liu [1], Cohen [2], and further theoretical studies [3-6] predicted that saturated $s p^{3}$-hybridized carbon nitride compounds have a bulk modulus comparable to or larger than that of diamond. Since then, the synthesis of low-compressible $\mathrm{C}_{3} \mathrm{~N}_{4}$ forms has been the main goal of studies related to superhard materials science [7]. In pioneering studies, high-pressure techniques have been proposed to transform a graphite-like carbon nitride ( $\mathrm{g}-\mathrm{CN}$ ) into a covalent $\mathrm{C}-\mathrm{N}$ solid with tetrahedral bonding similar to that observed in graphite-to-diamond process [2,3,8,9]. However, the proposed phases of $\mathrm{C}_{3} \mathrm{~N}_{4}$ are hardly observed during high-pressure syntheses involving various polymeric forms of amorphous carbon nitride [10-17]. An ideal precursor is still expected to obtain high-density carbon nitrides through high-pressure and high-temperature techniques.

On the basis of the analysis of chemical bonding geometries, we can observe that layered $\mathrm{C}-\mathrm{N}$ pyrolysate with an s-triazine $\left(\mathrm{C}_{3} \mathrm{~N}_{3}\right)$ unit should be preferred for the synthesis of high-density $\mathrm{CN}$ phases with a diamond-like $s p^{3}$ bond. As such, the s-triazine derivative molecule melam, which is one type of melamine pyrolysis product, has been extensively investigated [18-23]. Melam is formed by linking two melamine molecules [20]. In melamine pyrolysis, melam is in a highly active intermediate state and has a strong tendency to be converted into melem. Hence, pure melam is difficult to obtain through pyrolysis at atmospheric pressure. The insolubility of melamine and its pyrolysis products also causes difficulties in purification [24,25].

The pressure-driven structural transitions of molecular crystals have been widely investigated [26-29]. As pressure increases, atomic distance decreases, thereby inducing condensed phases and strong 
interactions among molecules. These interactions gradually become stronger and closer to inner molecules [30], indicating that aggregation is more likely to occur than a decomposition reaction at a given pressure. However, an increase in the pressure of ammonia during this reaction slows down the polymerization of melamine to melam by enhancing the re-transition into melamine and the formation of melem [21,22]. Thus, the high-pressure structural transition of melam should be further investigated.

In this work, a sample primarily composed of melam was synthesized from pure melamine at $350{ }^{\circ} \mathrm{C}$ under nitrogen flow. A high pressure of $5 \mathrm{GPa}$ was then applied to investigate the high-pressure phase transition of melam. The structures of the products at $5 \mathrm{GPa}$ and at a temperature of up to $700^{\circ} \mathrm{C}$ were studied through X-ray diffraction (XRD), infrared (IR) and Raman vibrational spectroscopies, and elemental analysis (EA). At $5 \mathrm{GPa}$, a phase transition from melam to melem did not occur before carbonization was obviously observed at $700{ }^{\circ} \mathrm{C}$. The content of residual or unreacted melamine decreased as temperature increased from $400{ }^{\circ} \mathrm{C}$ to $600{ }^{\circ} \mathrm{C}$ at $5 \mathrm{GPa}$. Thus, high-pressure purification of melam and further polymerization of the s-triazine-based structure could be predicted in carbon nitride at high pressure.

\section{Experimental Section}

\subsection{Sample Preparation}

A low-temperature $\left(350^{\circ} \mathrm{C}\right)$ deamination product (LTDP) was synthesized from pure melamine $\left(1 \mathrm{~g},>99 \%\right.$, Avocado) at $350{ }^{\circ} \mathrm{C}$ for $1 \mathrm{~h}$ in a quartz tube with a diameter of $35 \mathrm{~mm}$ under nitrogen flow in accordance with the procedure reported by B. Lotsch [20], E. Wirnhier [22], and Y. Kojima [12]. The procedure was repeated seven times to make the structural transition as complete as possible. The high-pressure pyrolysates of LTDP were obtained using a China-type CS $1 \mathrm{~B}(6 \times 8 \mathrm{MN})$ cubic anvil apparatus at $5 \mathrm{GPa}$ and $400-700{ }^{\circ} \mathrm{C}$.

\subsection{Characterizations}

An XRD (DMAX-2500/P, Rigaku, Japan) with Cu K $\alpha$ radiation (Bragg-Brentano geometry, $\lambda=0.15406 \mathrm{~nm}, 40 \mathrm{kV}, 200 \mathrm{~mA}$ ) was used to characterize the samples. The Fourier-transform infrared (FTIR) spectra of the samples were obtained by using a Bruker Equinox 55 FTIR spectrometer (Bruker, Madison, WI, USA) with an attenuated total reflectance (ATR) mode. Measurements were conducted on $\mathrm{KBr}$ pellets ( $1 \mathrm{mg}$ of sample; $100 \mathrm{mg}$ of $\mathrm{KBr}$; hand pressed with a capacity of $6 \mathrm{MPa}$ ) under ambient conditions between 400 and $4000 \mathrm{~cm}^{-1}$ in a transmission mode. The spectra were recorded at a resolution of $2 \mathrm{~cm}^{-1}$ and were averaged over 16 scans. Raman measurement was performed with a Renishaw InVia micro-Raman spectroscope (Renishaw, Wotton-under-Edge, Gloucestershire, UK) at laser radiations of 325, 532, and $633 \mathrm{~nm}$. Prior to each experiment, the Raman shift was calibrated using the well-defined peak of silicon wafer at about $520 \mathrm{~cm}^{-1}$. After calibration, Raman spectra were recorded with acquisition time of $50 \mathrm{~s}$ and accumulations of 10 to improve the signal-to-noise ratio (SNR). EA was performed by using a C/H/N elemental analyzer (Vario MACRO cube EL, Elementar, Langenselbold, Germany).

\section{Results and Discussion}

The XRD spectra of melamine, melam [22], and LTDP are shown in Figure 1b. Comparing these spectra, we observe that most of the XRD peaks of LTDP correspond to the diffraction of previously reported melam [22]. Four small peaks at $17.73^{\circ}, 27.10^{\circ}, 28.76^{\circ}$, and $29.78^{\circ}$ are assigned to the characteristic melamine (102) $,(12 \overline{1}),(112)$, and (013) diffractions, respectively. XRD analysis reveals that LTDP is mainly composed of melam and a small amount of residual melamine. Six unknown diffraction peaks are located in the range of $12^{\circ}-26^{\circ}$ of the XRD spectrum, indicating that an unknown $\mathrm{C}-\mathrm{N}$ or $\mathrm{C}-\mathrm{N}-\mathrm{H}$ structure may exist in the LTDP sample. The detailed XRD data of melamine and melam are listed in Tables S1 and S2, respectively. 


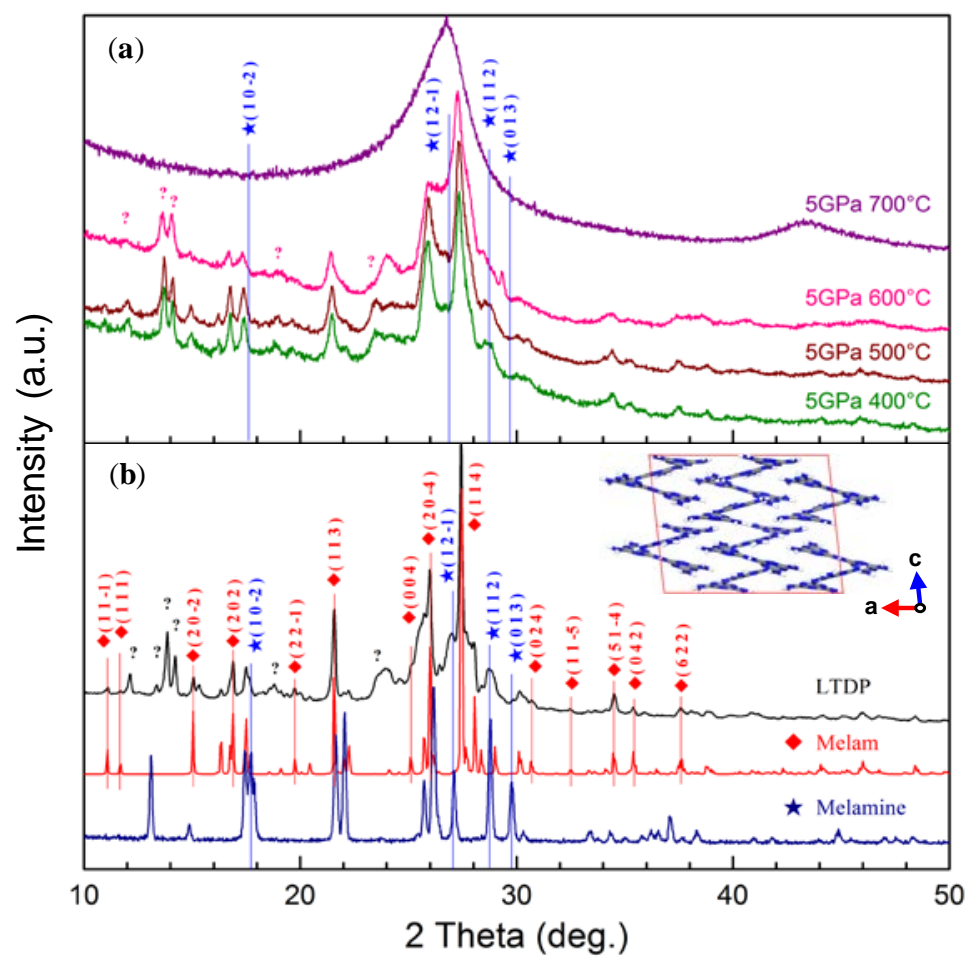

Figure 1. (a) XRD patterns of the samples treated at $5 \mathrm{GPa}$ and different temperatures $(400,500,600$, and $\left.700{ }^{\circ} \mathrm{C}\right)$; (b) XRD patterns of melamine, melam and LTDP sample. The inset in (b) Shows the crystal structure of melam.

Figure 1a illustrates that the structure of melam is effectively maintained in the treated LTDP sample at a high pressure of $5 \mathrm{GPa}$ and temperatures of $400-600{ }^{\circ} \mathrm{C}$. The pyrolytic behavior of melam at $5 \mathrm{GPa}$ is different from that at atmospheric pressure. Two alternative schemes of melam transformation $[20,23]$ have been proposed when melam is heated up to $600{ }^{\circ} \mathrm{C}$ at atmospheric pressure. In one of the schemes, melam transforms to melem and polymerizes into melon, which may further lose ammonia to form heptazine-based graphitic carbon nitride $\left(\mathrm{g}-\mathrm{C}_{3} \mathrm{~N}_{4}\right)$. In the other route, melam is directly polymerized into heptazine-based $\mathrm{g}-\mathrm{C}_{3} \mathrm{~N}_{4}$. At $5 \mathrm{GPa}$, the structure of melam in the LTDP

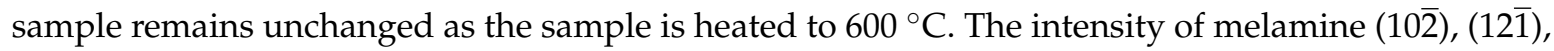
(112), and (013) diffraction peaks gradually decreases as temperature increases from $400{ }^{\circ} \mathrm{C}$ to $600{ }^{\circ} \mathrm{C}$, indicating that melamine still polymerizes at a high pressure. The typical pungent smell of ammonia when the samples are taken out from the crucible also indicates that melamine pyrolysis occurs. Our analysis suggests that high pressure can stabilize the melam structure without affecting the further pyrolysis of melamine. Therefore, this mechanism may be a valuable method for the synthesis of pure melam using as a carbon nitride precursor.

The positions of the unknown peaks in the XRD spectrum of LTDP remain unchanged as the pyrolysis temperature increases, indicating that the decomposition of $\mathrm{C}-\mathrm{N}$ or $\mathrm{C}-\mathrm{N}-\mathrm{H}$ products is also inhibited at a high pressure of $5 \mathrm{GPa}$. When the pyrolysis temperature reaches $700{ }^{\circ} \mathrm{C}$, the appearance of the peaks at $26.7^{\circ}$ and $43.5^{\circ}$ corresponding to the diffraction peaks of graphite (002) and (101) planes suggests that the LTDP sample is graphitized.

As the pyrolysis temperature increases, the color of the LTDP samples gradually changes from yellowish to yellow at $5 \mathrm{GPa}$ and $600{ }^{\circ} \mathrm{C}$ and black at $5 \mathrm{GPa}$ and $700{ }^{\circ} \mathrm{C}$ (Figure 2). The reported band gap energies of g- $\mathrm{C}_{3} \mathrm{~N}_{4}$ range from 2.4 to $2.85 \mathrm{eV}$ depending on different preparation conditions [31-35]. It is smaller than that of melamine [36,37]. The Raman spectra at different laser radiations (Figure S1) shows that no graphite phase exists in the high-pressure-treated samples at temperatures below $700{ }^{\circ} \mathrm{C}$. Thus, we tentatively conclude that changes in color are caused by the gradual decrease in melamine 
content with increasing temperature. Similar conclusions are also obtained from the XRD patterns of the samples.

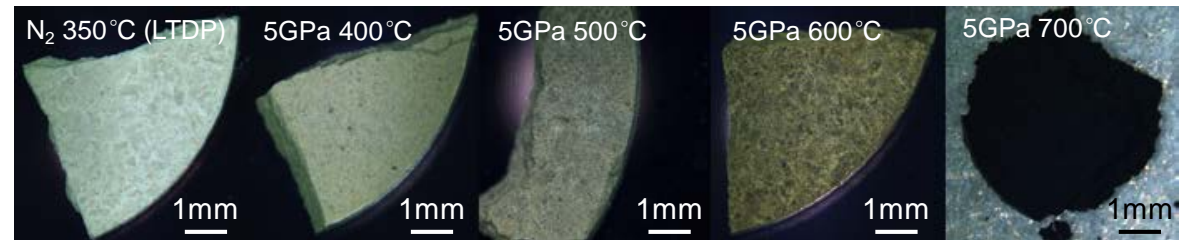

Figure 2. Optical image of LTDP and samples treated at $5 \mathrm{GPa}$ and $400-700{ }^{\circ} \mathrm{C}$.

The FTIR spectra of melamine, melam [20], LTDP, and the sample obtained at 5 GPa and at different temperatures are shown in Figure 3. The detailed FTIR data of melam [20], melamine [38], and the samples are listed in Table 1. The following characteristic vibrations in the FTIR spectrum

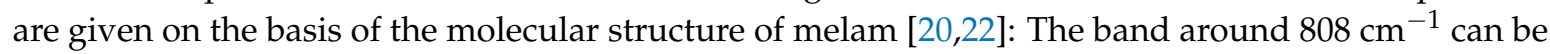
attributed to the bend vibration mode of the sextant ring; the absorption bands at $1250 \mathrm{~cm}^{-1}$ are the $\mathrm{NH}_{2}$ shearing vibration modes; the peaks around $1340 \mathrm{~cm}^{-1}$ can be inferred for the $\mathrm{C}-\mathrm{N}$ stretching modes; the absorption region between 1400 and $1700 \mathrm{~cm}^{-1}$ can be assigned to the coupling vibrations between $\mathrm{NH}_{2}$ shearing and $\mathrm{C}=\mathrm{N}$ stretching modes, thus providing evidence for the structure of the triazine ring to be retained; and the peaks found between 3100 and $3500 \mathrm{~cm}^{-1}$ verify the presence of $\mathrm{NH}$ or $\mathrm{NH}_{2}$ groups. The spectral lines and data analysis confirm that the main phase in the LTDP sample is melam, and this observation is consistent with the results of XRD analysis. Comparing the FTIR spectra of high-pressure samples in Figure 3, we can detect the same trend of phase transition as the XRD pattern. At below $600{ }^{\circ} \mathrm{C}$, the positions of the vibration peaks are almost the same as that of melam [21]. The basic s-triazine ring structure in the high-pressure samples remains undecomposed as the pyrolysis temperature increases. However, the slight deformation of CN rings at a high pressure of $5 \mathrm{GPa}$ causes the splitting of the infrared peaks for the same vibration mode. Hence, at temperatures of up to $600{ }^{\circ} \mathrm{C}$, the peaks in the wavenumber range of $1400-1700 \mathrm{~cm}^{-1}$ broaden significantly. The sample obtained at $700{ }^{\circ} \mathrm{C}$ shows a weak and featureless signal around $1630 \mathrm{~cm}^{-1}$ and $3440 \mathrm{~cm}^{-1}$ (see the zoomed spectrum in Figure S2), thereby indicating that the LTDP sample is likely to be an N-doped graphite [39].

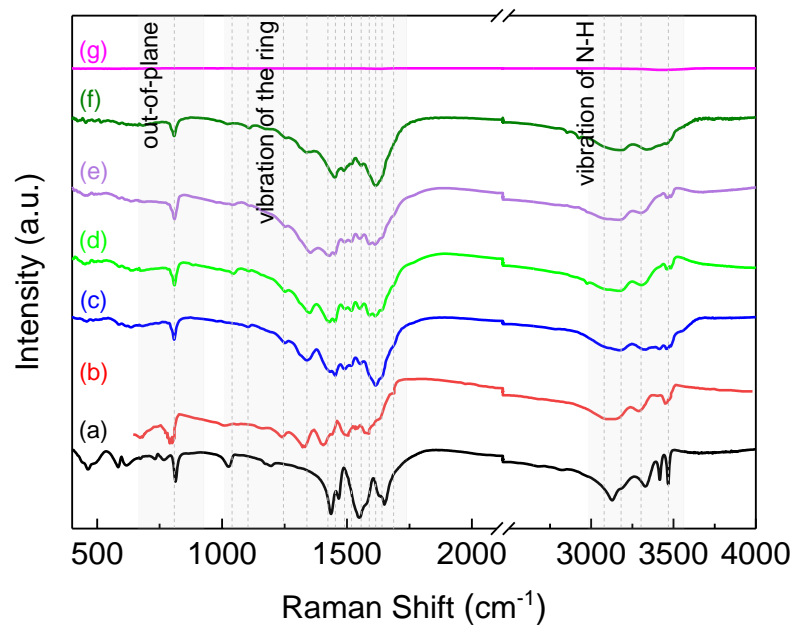

Figure 3. FTIR spectrum of melamine (a); melam (b); LTDP (c) and samples treated at $5 \mathrm{GPa}$ and $400{ }^{\circ} \mathrm{C}(\mathbf{d}) ; 500{ }^{\circ} \mathrm{C}(\mathbf{e}) ; 600{ }^{\circ} \mathrm{C}(\mathbf{f}) ;$ and $700{ }^{\circ} \mathrm{C}(\mathbf{g})$. 
Table 1. Vibrational frequencies $\left(\mathrm{cm}^{-1}\right)$ of melam, melamine, and LTDP

\begin{tabular}{|c|c|c|c|}
\hline Vibrations & Melam $\left(\mathrm{cm}^{-1}\right)$ & Melamine $\left(\mathrm{cm}^{-1}\right)$ & $\operatorname{LTDP}\left(\mathrm{cm}^{-1}\right)$ \\
\hline \multirow{4}{*}{$\mathrm{N}-\mathrm{H}$} & 3483.8 (vw) & $3468(\mathrm{~m})$ & $3485(\mathrm{vw})$ \\
\hline & 3456.5 (vw) & $3420(\mathrm{~m})$ & $3460(w)$ \\
\hline & $3300.2(w)$ & $3331(\mathrm{~m})$ & $3320(w)$ \\
\hline & $3165.4(w)$ & $3129(\mathrm{~m})$ & $3182(w)$ \\
\hline \multirow{14}{*}{ Ring } & $1687(\mathrm{vw})$ & - & - \\
\hline & $1639.5(\mathrm{~m})$ & - & - \\
\hline & $1610.0(\mathrm{~m})$ & - & - \\
\hline & $1583.8(\mathrm{~s})$ & 1650 (vs) & 1614 (vs) \\
\hline & $1545.8(\mathrm{~s})$ & 1548 (vs) & $1552(\mathrm{~m})$ \\
\hline & $1513.1(\mathrm{~s})$ & - & $1515(\mathrm{~m})$ \\
\hline & $1450.8(\mathrm{~s})$ & 1469 (vs) & 1452 (vs) \\
\hline & 1414.7 (vs) & 1438 (vs) & 1429 (vs) \\
\hline & 1338.4 (vs) & - & 1337 (vs) \\
\hline & $1249.8(\mathrm{~s})$ & - & $1250(\mathrm{~m})$ \\
\hline & $1174.9(w)$ & - & - \\
\hline & 1069.9 (vw) & - & - \\
\hline & $1021.1(\mathrm{vw})$ & - & - \\
\hline & $972.2(\mathrm{vw})$ & - & - \\
\hline \multirow{4}{*}{ Out-of-Plane } & 806.2 (vs) & 814 (vs) & 808 (vs) \\
\hline & $782.1(w)$ & - & - \\
\hline & $748.0(\mathrm{vw})$ & - & - \\
\hline & $682.6(\mathrm{~m})$ & - & $681(w)$ \\
\hline
\end{tabular}

w: Weak; vw: Very weak; m: Middle; s: Strong; vs: Very strong.

Figure 4 shows the elemental analysis (EA) of the variation in carbon, nitrogen, and hydrogen contents with increasing pyrolysis temperatures. The nitrogen and carbon contents slightly increase, whereas the hydrogen content decreases as the pyrolysis temperature increases to $600{ }^{\circ} \mathrm{C}$. This phenomenon is due to the polymerization of residual melamine in the sample. The dramatic increase in the carbon content occurs at $700{ }^{\circ} \mathrm{C}$, indicating a high degree of graphitization. This finding is consistent with the observations in the XRD and FTIR spectra. The N/C/H atomic ratios of LTDP and the samples treated at $5 \mathrm{GPa}$ and $400,500,600$, and $700{ }^{\circ} \mathrm{C}$ are listed in Table S3.

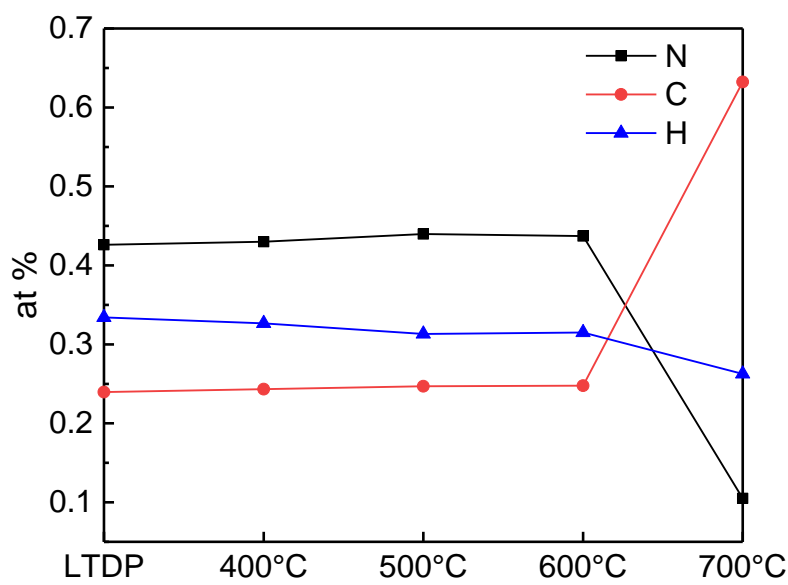

Figure 4. Elemental analysis of LTDP and the samples treated at $5 \mathrm{GPa}$ and $400-700{ }^{\circ} \mathrm{C}$.

\section{Conclusions}

This study investigates the high-pressure structural transition of melam at $5 \mathrm{GPa}$. Melam is synthesized through the multiple pyrolysis of melamine at $350{ }^{\circ} \mathrm{C}$ under nitrogen flow. During 
high-pressure processing, the structure of melam can be maintained on a preparative scale with a wide temperature range of $400-600{ }^{\circ} \mathrm{C}$, and the content of residual or unreacted melamine decreases as temperature increases. No evidence of further melam polymerization is obtained before carbonization occurs at $700{ }^{\circ} \mathrm{C}$. Our experimental findings reveal that the polymerization of $\mathrm{C}-\mathrm{N}-\mathrm{H}$ molecules is superior to their decomposition at high pressure. Thus, further polymerization of melam at a high pressure may be a promising strategy for the preparation of s-triazine-based carbon nitride precursors used for bulk CN synthesis.

Supplementary Materials: The following are available online at http:/ /www.mdpi.com/2079-4991/8/3/172/s1: Table S1: X-ray diffraction data of melamine; Table S2: X-ray diffraction data of melam cal.; Figure S1: Raman spectra of melam and the samples treated at $5 \mathrm{GPa}$ and $400,500,600$, and $700{ }^{\circ} \mathrm{C}$ at laser radiations of 325,532 , and $633 \mathrm{~nm}$; Figure S2. FTIR spectrum of the sample treated at $5 \mathrm{GPa}$ and $700{ }^{\circ} \mathrm{C}$; Table S3: Elemental analysis of melam (cal. and exp.) and the samples treated at $5 \mathrm{GPa}$ and different temperatures $\left(400,500,600\right.$, and $\left.700{ }^{\circ} \mathrm{C}\right)$.

Acknowledgments: This work was supported by National Natural Science Foundation of China (NSFC) (51722209, 51332005, 51525205), Project funded by China Postdoctoral Science Foundation (2017M620097) and 100 Talents Plan of Hebei Province (E2016100013).

Author Contributions: Xiaohong Yuan performed the experiments. Xiaohong Yuan, Kun Luo, Yingju Wu, Julong He, Zhisheng Zhao, and Dongli Yu participated in data analysis, discussion, and manuscript preparation. Zhisheng Zhao and Dongli Yu supervised and managed the project.

Conflicts of Interest: The authors declare no conflict of interest.

\section{References}

1. Cohen, M.L. Calculation of bulk moduli of diamond and zinc-blende solids. Phys. Rev. B 1985, 32, 7988-7991. [CrossRef]

2. Liu, A.Y.; Cohen, M.L. Prediction of new low compressibility solids. Science 1989, 245, 841-842. [CrossRef] [PubMed]

3. Teter, D.M.; Hemley, R.J. Low-Compressibility Carbon Nitrides. Science 1996, 271, 53-55. [CrossRef]

4. Sung, C.-M.; Sung, M. Carbon nitride and other speculative superhard materials. Mater. Chem. Phys. 1996, 43, 1-18. [CrossRef]

5. Dong, H.; Oganov, A.R.; Zhu, Q.; Qian, G.R. The phase diagram and hardness of carbon nitrides. Sci. Rep. 2015, 5, 9870. [CrossRef] [PubMed]

6. Pickard, C.J.; Salamat, A.; Bojdys, M.J.; Needs, R.J.; McMillan, P.F. Carbon nitride frameworks and dense crystalline polymorphs. Phys. Rev. B 2016, 94,1-11. [CrossRef]

7. Martin-Gil, J.; Martin-Gil, F.J.; Sarikaya, M.; Qian, M.; José-Yacamán, M.; Rubio, A. Evidence of a low compressibility carbon nitride with defect-zincblende structure. J. Appl. Phys. 1997, 81, 2555-2559. [CrossRef]

8. Kroke, E.; Schwarz, M. Novel group 14 nitrides. Coord. Chem. Rev. 2004, 248, 493-532. [CrossRef]

9. Dante, R.C.; Martín-Ramos, P.; Correa-Guimaraes, A.; Martín-Gil, J. Synthesis of graphitic carbon nitride by reaction of melamine and uric acid. Mater. Chem. Phys. 2011, 130, 1094-1102. [CrossRef]

10. Solozhenko, V. Equation of state and phase stability of turbostratic carbon nitride. J. Phys. Chem. Solids 2003, 64, 1265-1270. [CrossRef]

11. Fang, L.; Ohfuji, H.; Shinmei, T.; Irifune, T. Experimental study on the stability of graphitic $\mathrm{C}_{3} \mathrm{~N}_{4}$ under high pressure and high temperature. Diam. Relat. Mater. 2011, 20, 819-825. [CrossRef]

12. Kojima, Y.; Ohfuji, H. Structure and stability of carbon nitride under high pressure and high temperature up to 125 GPa and 3000 K. Diam. Relat. Mater. 2013, 39, 1-7. [CrossRef]

13. Badding, J.V.; Nesting, D.C. Thermodynamic analysis of the formation of carbon nitrides under pressure. Chem. Mater. 1996, 8, 535-540. [CrossRef]

14. Xu, M.; Wang, S.; Yin, G.; Li, J.; Zheng, Y.; Chen, L.; Jia, Y. Optical properties of cubic $\mathrm{Ti}_{3} \mathrm{~N}_{4}, \mathrm{Zr}_{3} \mathrm{~N}_{4}$, and $\mathrm{Hf}_{3} \mathrm{~N}_{4}$. Appl. Phys. Lett. 2006, 89, 151908. [CrossRef]

15. Zinin, P.V.; Ming, L.C.; Sharma, S.K.; Hong, S.M.; Xie, Y.; Irifune, T.; Shinmei, T. Synthesis of new cubic $\mathrm{C}_{3} \mathrm{~N}_{4}$ and diamond-like $\mathrm{BC}_{3}$ phases under high pressure and high temperature. J. Phys. Conf. Ser. 2008, 121, 62002. [CrossRef] 
16. Miller, T.S.; Jorge, A.B.; Suter, T.M.; Sella, A.; Corà, F.; McMillan, P.F. Carbon nitrides: Synthesis and characterization of a new class of functional materials. Phys. Chem. Chem. Phys. 2017, 19, 15613-15638. [CrossRef] [PubMed]

17. Chamorro-Posada, P.; Martín-Ramos, P.; Sánchez-Arévalo, F.M.; Dante, R.C. Molecular dynamics simulations of nanosheets of polymeric carbon nitride and comparison with experimental observations. Fuller. Nanotub. Carbon Nanostruct. 2018, 26, 137-144. [CrossRef]

18. May, H. Pyrolysis of melamine. J. Appl. Chem. 1959, 9, 340-344. [CrossRef]

19. Costa, L.; Camino, G. Thermal behaviour of melamine. J. Therm. Anal. 1988, 34, 423-429. [CrossRef]

20. Lotsch, B.V.; Schnick, W. New Light on an Old Story: Formation of Melam during Thermal Condensation of Melamine. Chem. A Eur. J. 2007, 13, 4956-4968. [CrossRef] [PubMed]

21. Sattler, A.; Pagano, S.; Zeuner, M.; Zurawski, A.; Gunzelmann, D.; Senker, J.; Müller-Buschbaum, K.; Schnick, W. Melamine-Melem Adduct Phases: Investigating the Thermal Condensation of Melamine. Chem. A Eur. J. 2009, 15, 13161-13170. [CrossRef] [PubMed]

22. Wirnhier, E.; Mesch, M.B.; Senker, J.; Schnick, W. Formation and characterization of melam, melam hydrate, and a melam-melem adduct. Chem. A Eur. J. 2013, 19, 2041-2049. [CrossRef] [PubMed]

23. Jürgens, B.; Irran, E.; Senker, J.; Kroll, P.; Müller, H.; Schnick, W. Melem (2,5,8-Triamino-tris-triazine), an Important Intermediate during Condensation of Melamine Rings to Graphitic Carbon Nitride: Synthesis, Structure Determination by X-ray Powder Diffractometry, Solid-State NMR, and Theoretical Studies. J. Am. Chem. Soc. 2003, 125, 10288-10300. [CrossRef] [PubMed]

24. Fina, F.; Callear, S.K.; Carins, G.M.; Irvine, J.T.S. Structural Investigation of Graphitic Carbon Nitride via XRD and Neutron Diffraction. Chem. Mater. 2015, 27, 2612-2618. [CrossRef]

25. Gillan, E.G. Synthesis of Nitrogen-Rich Carbon Nitride Networks from an Energetic Molecular Azide Precursor. Chem. Mater. 2000, 12, 3906-3912. [CrossRef]

26. Horibe, T.; Kusaba, K.; Niwa, K.; Hasegawa, M.; Yasuda, K.; Ishigami, R. Molecular routes syntheses of graphite-like C\&ndash;N compounds with various N/C ratios in high pressure and temperature. J. Ceram. Soc. Jpn. 2016, 124, 1013-1016. [CrossRef]

27. Goglio, G.; Foy, D.; Demazeau, G. State of Art and recent trends in bulk carbon nitrides synthesis. Mater. Sci. Eng. R Rep. 2008, 58, 195-227. [CrossRef]

28. Zhang, Z.; Leinenweber, K.; Bauer, M.; Garvie, L.A.J.; McMillan, P.F.; Wolf, G.H. High-Pressure Bulk Synthesis of Crystalline $\mathrm{C}_{6} \mathrm{~N}_{9} \mathrm{H}_{3} \cdot \mathrm{HCl}$ : A Novel $\mathrm{C}_{3} \mathrm{~N}_{4}$ Graphitic Derivative. J. Am. Chem. Soc. 2001, 123, 7788-7796. [CrossRef] [PubMed]

29. Horvath-Bordon, E.; Riedel, R.; McMillan, P.F.; Kroll, P.; Miehe, G.; Van Aken, P.A.; Zerr, A.; Hoppe, P.; Shebanova, O.; McLaren, I.; et al. High-pressure synthesis of crystalline carbon nitride imide, $\mathrm{C}_{2} \mathrm{~N}_{2}(\mathrm{NH})$. Angew. Chem. Int. Ed. 2007, 46, 1476-1480. [CrossRef] [PubMed]

30. Ma, H.A.; Jia, X.; Cui, Q.L.; Pan, Y.W.; Zhu, P.W.; Liu, B.B.; Liu, H.J.; Wang, X.C.; Liu, J.; Zou, G.T. Crystal structures of $\mathrm{C}_{3} \mathrm{~N}_{6} \mathrm{H}_{6}$ under high pressure. Chem. Phys. Lett. 2003, 368, 668-672. [CrossRef]

31. Hong, J.; Xia, X.; Wang, Y.; Xu, R. Mesoporous carbon nitride with in situ sulfur doping for enhanced photocatalytic hydrogen evolution from water under visible light. J. Mater. Chem. 2012, 22, 15006. [CrossRef]

32. Zhang, J.; Sun, J.; Maeda, K.; Domen, K.; Liu, P.; Antonietti, M.; Fu, X.; Wang, X. Sulfur-mediated synthesis of carbon nitride: Band-gap engineering and improved functions for photocatalysis. Energy Environ. Sci. 2011, 4, 675-678. [CrossRef]

33. Cui, Y.; Ding, Z.; Liu, P.; Antonietti, M.; Fu, X.; Wang, X. Metal-free activation of $\mathrm{H}_{2} \mathrm{O}_{2}$ by g- $\mathrm{C}_{3} \mathrm{~N}_{4}$ under visible light irradiation for the degradation of organic pollutants. Phys. Chem. Chem. Phys. 2012, 14, 1455-1462. [CrossRef] [PubMed]

34. Chen, X.; Zhou, B.; Yang, S.; Wu, H.; Wu, Y.; Wu, L.; Pan, J.; Xiong, X. In situ construction of an $\mathrm{SnO}_{2} / \mathrm{g}-\mathrm{C}_{3} \mathrm{~N}_{4}$ heterojunction for enhanced visible-light photocatalytic activity. RSC Adv. 2015, 5, 68953-68963. [CrossRef]

35. Martín-Ramos, P.; Martín-Gil, J.; Dante, R.C.; Vaquero, F.; Navarro, R.M.; Fierro, J.L.G. A simple approach to synthesize $\mathrm{g}-\mathrm{C}_{3} \mathrm{~N}_{4}$ with high visible light photoactivity for hydrogen production. Int. J. Hydrogen Energy 2015, 40, 7273-7281. [CrossRef]

36. De Lourdes Mendes Finete, V.; Martins Gouvêa, M.; De Carvalho Marques, F.F.; Duarte Pereira Netto, A. Characterization of newfound natural luminescent properties of melamine, and development and validation of a method of high performance liquid chromatography with fluorescence detection for its determination in kitchen plastic ware. Talanta 2014, 123, 128-134. [CrossRef] [PubMed] 
37. Bian, J.; Li, J.; Kalytchuk, S.; Wang, Y.; Li, Q.; Lau, T.C.; Niehaus, T.A.; Rogach, A.L.; Zhang, R.-Q. Efficient Emission Facilitated by Multiple Energy Level Transitions in Uniform Graphitic Carbon Nitride Films Deposited by Thermal Vapor Condensation. Chem. Phys. Chem. 2015, 16, 954-959. [CrossRef] [PubMed]

38. Yuan, X.; Luo, K.; Zhang, K.; He, J.; Zhao, Y.; Yu, D. Combinatorial Vibration-Mode Assignment for the FTIR Spectrum of Crystalline Melamine: A Strategic Approach toward Theoretical IR Vibrational Calculations of Triazine-Based Compounds. J. Phys. Chem. A 2016, 120, 7427-7433. [CrossRef] [PubMed]

39. Ferrari, A.C.; Rodil, S.E.; Robertson, J.; Rodil, S.E.; Robertson, J. Interpretation of infrared and Raman spectra of amorphous carbon nitrides. Phys. Rev. B Condens. Matter Mater. Phys. 2003, 67, 1-20. [CrossRef]

(C) 2018 by the authors. Licensee MDPI, Basel, Switzerland. This article is an open access article distributed under the terms and conditions of the Creative Commons Attribution (CC BY) license (http:/ / creativecommons.org/licenses/by/4.0/). 